\title{
Validation of the doubly-labelled water technique in the domestic dog (Canis familiaris)
}

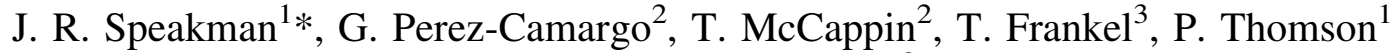 \\ and V. Legrand-Defretin ${ }^{2} \dagger$ \\ ${ }^{1}$ Department of Zoology, University of Aberdeen, Aberdeen AB24 2TZ, UK \\ ${ }^{2}$ Waltham Centre for Pet Nutrition, Waltham-on-the-Wolds, Melton Mowbray, Leicestershire LE14 4RT, UK \\ ${ }^{3}$ School of Agriculture, La Trobe University, Bundoora, Victoria 3083, Australia
}

(Received 25 February 2000 - Revised 30 June 2000 - Accepted 31 July 2000)

\begin{abstract}
We validated doubly-labelled water (DLW) by comparison to indirect calorimetry and food intake-mass balance in eight Labrador dogs (24-32 kg) over $4 \mathrm{~d}$. We used several alternative equations for calculating $\mathrm{CO}_{2}$ production, based on the single- and two-pool models and used two alternative methods for evaluating the elimination constants: two-sample and multiplesampling. In all cases the DLW technique overestimated the direct estimate of $\mathrm{CO}_{2}$ production. The greatest overestimates occurred with the single-pool model. Using two samples, rather than multiple samples, to derive the elimination constants produced slightly more discrepant results. Discrepancies greatly exceeded the measured analytical precision of the DLW estimates. The higher values with DLW probably occurred because the dogs were extremely active during the $1 \mathrm{~h}$ in each 24 spent outside the chamber. Estimates of $\mathrm{CO}_{2}$ production from food intake-mass balance, which include this activity, produced a much closer comparison to DLW (lowest mean discrepancy $0.3 \%$ using the observed group mean dilution space ratio and an assumption that the mass changes reflected changes in hydration for all except one animal). We recommend an equilibration time of $6 \mathrm{~h}$ and use of the two-pool model based on the observed population dilution space for future studies of energy demands in dogs of this body mass.
\end{abstract}

Energy expenditure: Calorimetry: Doubly-labelled water: Dogs

The doubly-labelled water (DLW) technique was developed in the 1950s (Lifson et al. 1955). It provides an estimate of the $\mathrm{CO}_{2}$ production of free-living subjects from the differential elimination of isotopic labels (normally ${ }^{2} \mathrm{H}$ or ${ }^{3} \mathrm{H}$ and ${ }^{18} \mathrm{O}$ ) introduced into body water. ${ }^{2} \mathrm{H}$ is eliminated from the body primarily as a consequence of water input and output. However, ${ }^{18} \mathrm{O}$ is not only eliminated by the flow of water through the body, but also by the influx of respiratory $\mathrm{O}_{2}$ and efflux of $\mathrm{CO}_{2}$. This occurs because the $\mathrm{O}$ in dissolved $\mathrm{CO}_{2}$ in the blood is in complete isotopic exchange equilibrium with the $\mathrm{O}$ in body water (Lifson et al. 1949). Consequently, the difference in their elimination should predominantly reflect the rate of $\mathrm{CO}_{2}$ production. Until the early 1980s the method was utilised primarily as a tool for investigating the energy demands of small animals, notably birds (e.g. Bryant \& Westerterp, 1983), mammals (Mullen, 1970) and reptiles (Nagy, 1972). Since 1982, when the first measurements of $\mathrm{CO}_{2}$ production in humans were published (Schoeller \& Santen, 1982), use of the technique has expanded exponentially
(Speakman, 1997) and there has been renewed attention focused on its underlying assumptions (reviewed in Lifson \& McClintock, 1966; Coward et al. 1985; Prentice, 1990; Speakman, 1997).

One issue of interest has been the most appropriate equation for calculation of $\mathrm{CO}_{2}$ production from measurements of the elimination constants and dilution spaces (pool sizes) of the two isotopes. Two dominant alternatives have been employed. The first multiplies the difference in elimination constants by the body water pool size, evaluated from the oxygen dilution space (the single-pool model; Lifson \& McClintock, 1966). In the second approach each elimination constant is multiplied by its own dilution space (Coward et al. 1985; Schoeller et al. 1986; the two-pool model). Since the mid-1980s almost all DLW studies of humans have employed the two-pool model, whereas the majority of animal studies have used the original single-pool formulation. The theoretical interrelationships of these approaches have been explored (Speakman, 1997), and the most suitable model will

\footnotetext{
Abbreviations: DLW, doubly-labelled water.

* Corresponding author: Professor J. R. Speakman, fax + 441224 272396, email J.Speakman@aberdeen.ac.uk

†Current address: Waltham France, Unisabi, SNC Boite Postale No. 7, 45550 Saint-Denis-De-L'Hotel, France.
} 
depend on the extent to which there are minor irreversible losses of $\mathrm{H}$ (for example, exchange onto compounds such as urea and faeces, and elimination from the body), compared with the extent of minor reversible exchanges of $\mathrm{H}$ (such as exchangeable sites on exposed protein and fat). This balance in reversible and irreversible exchange will favour use of the single-pool model in small animals, but use of the two-pool formulation in larger animals (Speakman, 1997).

As long as applications of the technique to small animals used the single-pool model, but when humans were studied the two-pool model was employed, this technical difference would probably have made little practical difference. However, increasingly, groups who have previously worked on small animals are expanding their work to larger animals (e.g. Fancy et al. 1986; Nagy et al. 1990; Arnould et al. 1996) and groups which have previously studied only humans are also expanding their work to study smaller animals (e.g. Bergmann et al. 1989; Midwood et al. 1993). Each group has transferred the technology, methods of analysis and calculation to the different field of application. We are now faced with a situation where different groups are applying the DLW technique to animals of similar size, but are applying different methods of calculation, which differ significantly in the estimates of $\mathrm{CO}_{2}$ production that they yield: e.g. studies of ruminants employing single pool (Nagy et al. 1990) or two-pool calculations (Midwood et al. 1993).

This changing pattern in applications raises an important question. How should we calculate the $\mathrm{CO}_{2}$ production of animals which have body masses between those of 'small' mammals $(<1 \mathrm{~kg})$ and adult humans (Speakman, 1993)? This problem is not resolved by validation studies of the method on young humans (reviewed in Roberts, 1989), because these have abnormally low dilution space ratios when compared with adult humans and animals (Wells et al. 1998). Recent validation studies comparing the DLW technique to indirect calorimetry, and employing the different methods of calculation (Bevan et al. 1995; Boyd et al. 1995) have indicated support for the two-pool model in mammals weighing greater than $2 \mathrm{~kg}$, but the single-pool model in smaller animals (Tiebout \& Nagy, 1991). However, in both the cases where the two-pool model was favoured unusual circumstances reduced the precision of the DLW technique: in one case (Bevan et al. 1995) because of an extremely high water flux, and in the second (Boyd et al. 1995) because of a short experimental duration. These unusual situations might not therefore represent the most ideal situations for validation of the different calculations.

The daily energy requirements of domestic dogs (Canis familiaris) are of interest for a variety of reasons. Dogs are involved in many areas of service work and sporting activities for man. Evaluating the energy demands of dogs when engaged in their routine work or sporting activities is a key aspect of evaluating their nutritional requirements to ensure peak performance (Burger \& Johnson, 1990). Moreover, dogs are valuable companion animals, ownership of which has been shown to have a wide range of therapeutic benefits including recuperation from trauma (Robinson, 1995). However, they are prone to obesity if overfed, which may shorten their lifespan. Evaluating energy demands of dogs in the home setting is therefore also of importance in the context of providing sound nutritional advice to pet owners. The DLW technique provides an obvious tool for making measurements appropriate to these applications.

Should applications of the DLW technique to larger domestic dogs employ the two-pool or the single pool methods of calculation? This is not a trivial issue. In a recent application (Ballevre et al. 1994) of the technique to a single domestic dog weighing $30 \mathrm{~kg}$, for example, it was concluded that previous evaluations of the energy demands of dogs, based on food intake, may have been overestimated by about $15 \%$. In this latter study, the two-pool model was used for the calculation. However, if the singlepool model was more appropriate for these animals the calculated energy demands would have been higher, and probably not significantly different to previous recommendations. A primary conclusion of the study by Ballevre et al. (1994) was therefore that a validation of the technique needs to be performed on domestic dogs, comparing the alternative approaches to calculation, to simultaneous indirect calorimetry. In the present paper we present such a validation on Labrador dogs weighing 24-32 kg.

\section{Methods \\ Animals}

Eight Labradors, bred and reared at the Waltham Centre for Pet Nutrition, were used in this study. Installations, housing and husbandry methods have been previously described (Loveridge, 1994). The dogs included four males and four females with a mean age of 34 months (17-50 months). Body mass varied between 23.5 and $32.1 \mathrm{~kg}$ and averaged $28.4 \mathrm{~kg}$. All the dogs were inspected by a vet prior to and throughout each experiment and were judged fit and healthy. All experiments were licensed by the UK Home Office.

\section{Protocol}

The $\mathrm{CO}_{2}$ production of each Labrador was measured for $4 \mathrm{~d}$, using three techniques simultaneously: (a) indirect calorimetry: (b) inferred from food intake and mass balance; (c) the DLW technique. Being social animals $4 \mathrm{~d}$ was the maximum period that dogs could be isolated in an indirect calorimeter without undue stress. It was necessary to remove the dogs from the calorimeter for $1 \mathrm{~h}$ each day. During this hour we collected blood samples for subsequent isotope analysis. The same protocol was followed for all eight animals. On day 1 the dogs were weighed (Sartorius F150 balance, Sartorius AG, Longmead, Surrey, UK) and a blood sample taken from a cephalic vein (about $2 \mathrm{ml}$ ) to estimate background isotope enrichments. A known mass of DLW $(0.2 \mathrm{~g} / \mathrm{kg}$ body weight) was administered via the other cephalic vein. The syringe used was weighed immediately before and after administration (Sartorius 4-fig balance). The DLW was a mixture of two parts $97 \%{ }^{18} \mathrm{O}$-enriched water (Enritech Ltd, Tel Aviv, Israel) and one part $99.9 \%{ }^{2} \mathrm{H}$-enriched 
water (MSD Isotopes Inc., Croydon, UK), made isotonic with sodium chloride. Blood samples were taken from alternate cephalic veins hourly for the next $6 \mathrm{~h}$, during which period the dogs were without access to food or water.

After the $6 \mathrm{~h}$ equilibration period, each dog was leashwalked for 15-20 min. It was then placed into the calorimeter chamber with a weighed daily portion of food (400-800 g depending on the individual dog) and water $a d$ libitum for $23 \mathrm{~h}$. During this time $\mathrm{O}_{2}$ consumption and $\mathrm{CO}_{2}$ production were monitored continuously. After each $23 \mathrm{~h}$ period in the calorimeter chamber, the animals were removed, body mass measured and a further blood sample taken. The dogs were examined by a veterinary surgeon, and leash-walked for 15-20 min before returning to the calorimeter for the next $23 \mathrm{~h}$ period. While the dog was absent from the chamber any faeces it had produced were removed and weighed and the chamber cleaned. The mass of the food presented to the dogs was always completely eaten. After the fourth $23 \mathrm{~h}$ period in the calorimeter chamber, body mass was measured and the final blood sample taken.

During the study, all dogs were fed on Pedigree Formula Adult Menu, which is a complete dry diet with the following composition $(\mathrm{g} / \mathrm{kg})$ : protein 250 ; fat 100 ; carbohydrate 480; moisture 80; fibre 15 and ash 75 (Waltham Centre for Pet Nutrition, unpublished results). The metabolisable energy content of this food was $14.54 \mathrm{~kJ} / \mathrm{g}$ (Waltham Centre for Pet Nutrition, unpublished results).

\section{Sample handling}

All injections and blood sampling was carried out by the same animal technician. Blood samples (approx. 2.0 ml) were collected in heparinised glass vacutainers. From this sample, four glass capillaries $(100 \mu \mathrm{l})$ were filled and heat sealed, while the remainder of the blood was centrifuged to separate the plasma. Capillaries were refrigerated until analysis, whereas plasma samples were frozen as a back up. For each dog a dilution of the injectate was also made by injecting a weighed quantity $(c .0 \cdot 1 \mathrm{ml})$ of the injectate into a weighed quantity of tap water $(c .500 \mathrm{ml})$. This dilution was used to evaluate the enrichment of isotopes in the injectate. Samples of the mix of tap water and injectate were treated in exactly the same manner as the blood samples as suggested by Prentice (1990).

\section{Calorimeter system}

The calorimeter was an air-tight chamber $\left(4.72 \mathrm{~m}^{3}\right.$ internal volume) with the internal temperature maintained at $18 \pm$ $1^{\circ} \mathrm{C}$ by a propylene glycol air-cooling system. A timer provided $14 \mathrm{~h}$ light per day and the dogs were continuously videoed while in the chamber. Air flow (around $100 \mathrm{l} / \mathrm{min}$ ) through the chamber was provided by three pumps (Fan Type 9M S8, Air control Installations/Chard/Ltd, Chard, UK). One forced air into the chamber while the other two collected air from the outlet. The cooler and a drying column packed with $200 \mathrm{~g}$ fused granular calcium chloride (BDH, Derby, UK) removed any moisture from the outflow. Air flow was continuously recorded (Chell Instruments Ltd, Norfolk, UK) and a sub-sample of $2.5 \mathrm{l} /$ min was diverted for analysis to a 1490 Infrared $\mathrm{CO}_{2}$ Analyser and a 540A $\mathrm{O}_{2}$ Analyser (both from Servomex, Crowborough, UK).

Every hour, under computer control, air was sampled from the air inlet of the chamber to determine a baseline, and two calibration gases $\left(\mathrm{a}: \mathrm{O}_{2} 20.00 \%\right.$ and $\mathrm{CO}_{2} 1.000 \%$ in $\mathrm{N}_{2}$; b: $\mathrm{O}_{2} 20.96 \%$ and $\mathrm{CO}_{2} 0.040 \%$ in $\mathrm{N}_{2}$. Air Products, Gold Standard, Basingstoke, UK) were passed through the detectors for recalibration. The detectors were measuring air from the inlet and calibration gases for $8 \mathrm{~min}$ in $1 \mathrm{~h}$. For the remaining $52 \mathrm{~min}$ in $1 \mathrm{~h}$, the detectors sampled the air from the outlet of the chamber. A period of $1 \mathrm{~h}$ was allowed for the equilibration of gases in the chamber before recording data. Simulated infusion tests of the system revealed $100.5 \%$ recovery of $\mathrm{O}_{2}$ and $97.4 \%$ recovery of $\mathrm{CO}_{2}$. All $\mathrm{O}_{2}$ consumption and $\mathrm{CO}_{2}$ production estimates were corrected to standard temperature and pressure data.

\section{Sample preparation}

All sample preparation, isotope analyses and calculations were performed blind of the calorimetry data. Samples (100 $\mu$ l flame-sealed capillaries) were vacuum distilled into pasteur pipettes (Nagy, 1983). The resultant distillate was used either for determination of ${ }^{18} \mathrm{O}$ or ${ }^{2} \mathrm{H}$ content. For ${ }^{18} \mathrm{O}$ analysis $10-20 \mu \mathrm{l}$ aliquots of the sample were pipetted into weighed (Ohaus 4-fig balance, Ohaus, Florham Park, NJ, USA) vacutainers which were immediately reweighed to give the mass of sample, and the vacutainer resealed. The samples were frozen under liquid $\mathrm{N}_{2}$ and the air above the sample removed using a vacuum rig. Isotopically characterised $\mathrm{CO}_{2}(4 \mathrm{ml})$ from a cylinder (CP grade gases; BOC Ltd, Chertsey, Surrey, UK) were injected into each vacutainer using a $10 \mathrm{ml}$ gas-tight Hamilton syringe. The sample and $\mathrm{CO}_{2}$ were then equilibrated for $16 \mathrm{~h}$ at $60^{\circ} \mathrm{C}$, a series of validation studies having shown that this time and temperature resulted in complete equilibration. Following equilibration the $\mathrm{CO}_{2}$ was cryogenically separated from the water and flame-sealed into a glass 'break-seal' vessel until analysed. We found no difference in the estimated isotope enrichments of standard materials when using vacutainers direct from the manufacturer or vacutainers that had been re-evacuated prior to use. This indicates that contamination of vacutainers was not a problem.

For analysis of ${ }^{2} \mathrm{H}$ content aliquots $(1.5 \mu \mathrm{l})$ of the distilled water were sealed into capillaries and then flamesealed into evacuated vessels with approximately $20 \mathrm{mg}$ 'optimally contaminated Zn' (J. M. Hayes, Bloomington, IN, USA). The combined vessels were then placed in a muffle furnace at $590^{\circ} \mathrm{C}$ for $1.5 \mathrm{~h}$. At these temperatures the water sample expanded and the internal capillary ruptured, allowing water and $\mathrm{Zn}$ to react to produce $\mathrm{H}_{2}$ gas. The break-seal vessels containing the reaction products were then available for analysis by MS without further processing. This system, which we have developed at the University of Aberdeen, ensures the water and $\mathrm{Zn}$ do not react until they are at high temperature. This avoids reaction of water and $\mathrm{Zn}$ at room temperature, potentially producing zinc hydrides, which has been highlighted 
$\operatorname{Dog} 1$

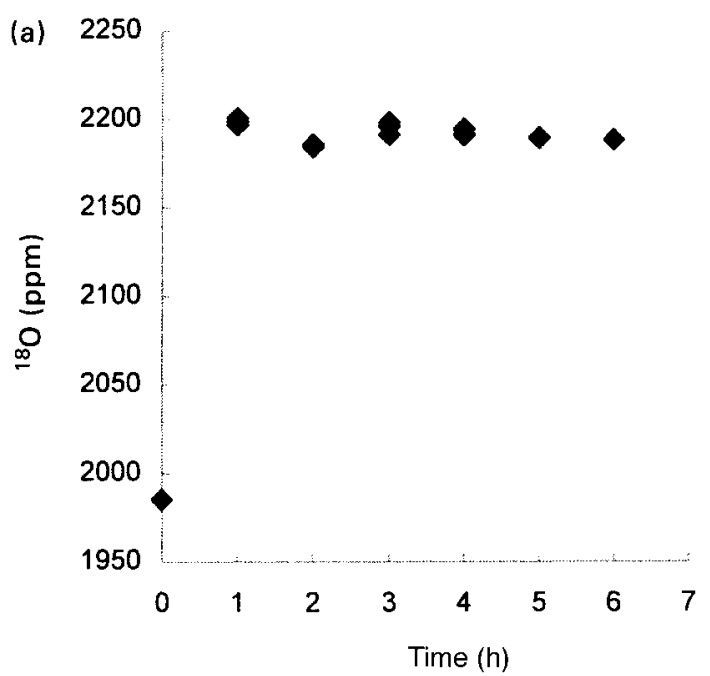

$\operatorname{Dog} 2$

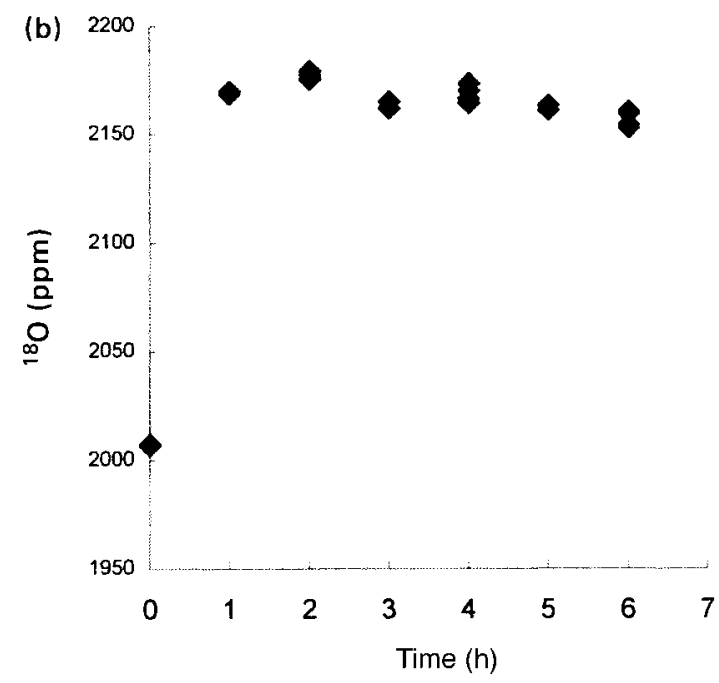

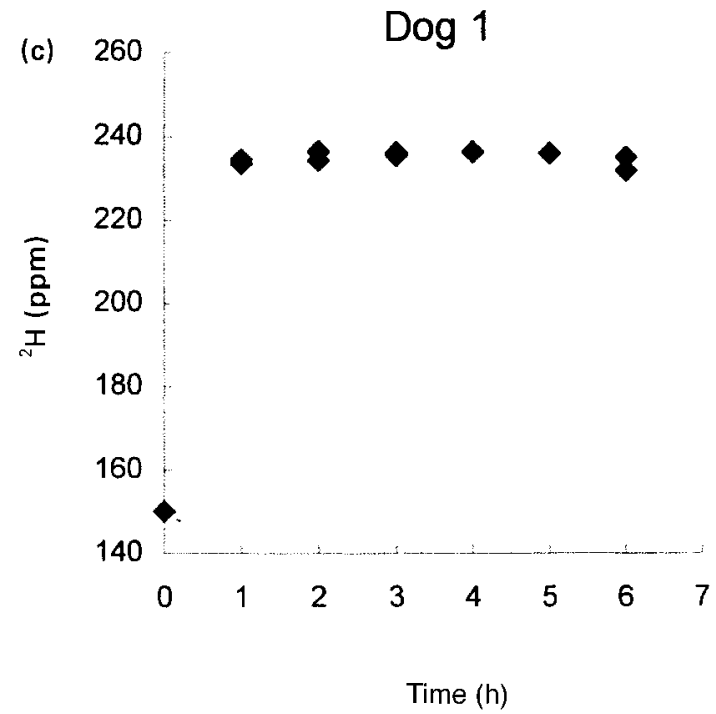

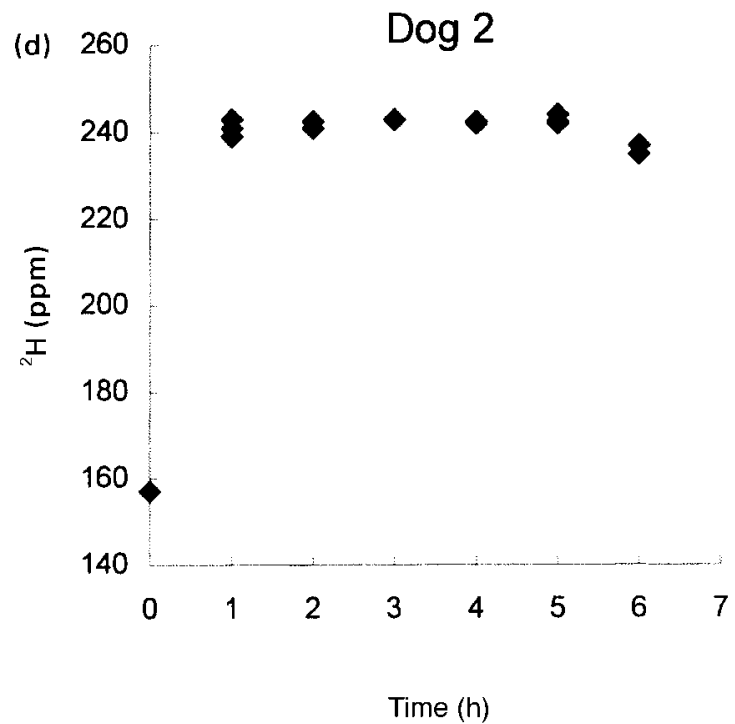

Fig. 1. Four examples of the pattern of isotope equilibration during the first $6 \mathrm{~h}$ postdosing in two Labrador dogs compared with the pre-dosing level of enrichment. The top two panels are ${ }^{18} \mathrm{O}$ and the bottom two panels ${ }^{2} \mathrm{H}$. The dogs were intravenously injected at time 0 with a mix of both ${ }^{18} \mathrm{O}$ and ${ }^{2} \mathrm{H}$ and blood samples were taken at hourly intervals thereafter. At this scale both the isotopes appear to rapidly flood into the exchangeable dilution space over the first hour and are constant thereafter.

previously as a potential problem with using $\mathrm{Zn}$ as a reduction agent for MS analysis (Coleman et al. 1982).

\section{$M S$}

Samples were analysed using a gas source isotope-ratio MS (VG Optima, Micromass, Manchester, UK) using isotopically characterised cylinder gases of $\mathrm{CO}_{2}$ and $\mathrm{H}_{2}$ (CP grade gases; BOC Ltd) in the reference channel. These cylinder gases were characterised relative to the isotopic standards standard mean ocean water (SMOW) and standard light arctic precipitate (SLAP) (de Wit et al. 1980: supplied by International Atomic Energy Authority, Vienna, Austria). Both reference gases were slightly depleted relative to SMOW $\left({ }^{18} \mathrm{O}:{ }^{16} \mathrm{O}\right.$ for $\mathrm{CO}_{2}$ gas 0.001937 and ${ }^{2} \mathrm{H}:{ }^{1} \mathrm{H}$ for $\mathrm{H}_{2}$ gas 0.000137). In each batch of samples for analysis we ran our own laboratory standards to ensure day-to-day variation in performance of the analyser was not a significant factor. All isotope enrichments were measured in $\delta / \mathrm{ml}$ relative to the working standards and then converted to ppm using the established ratios for these reference materials. 
Dog 1
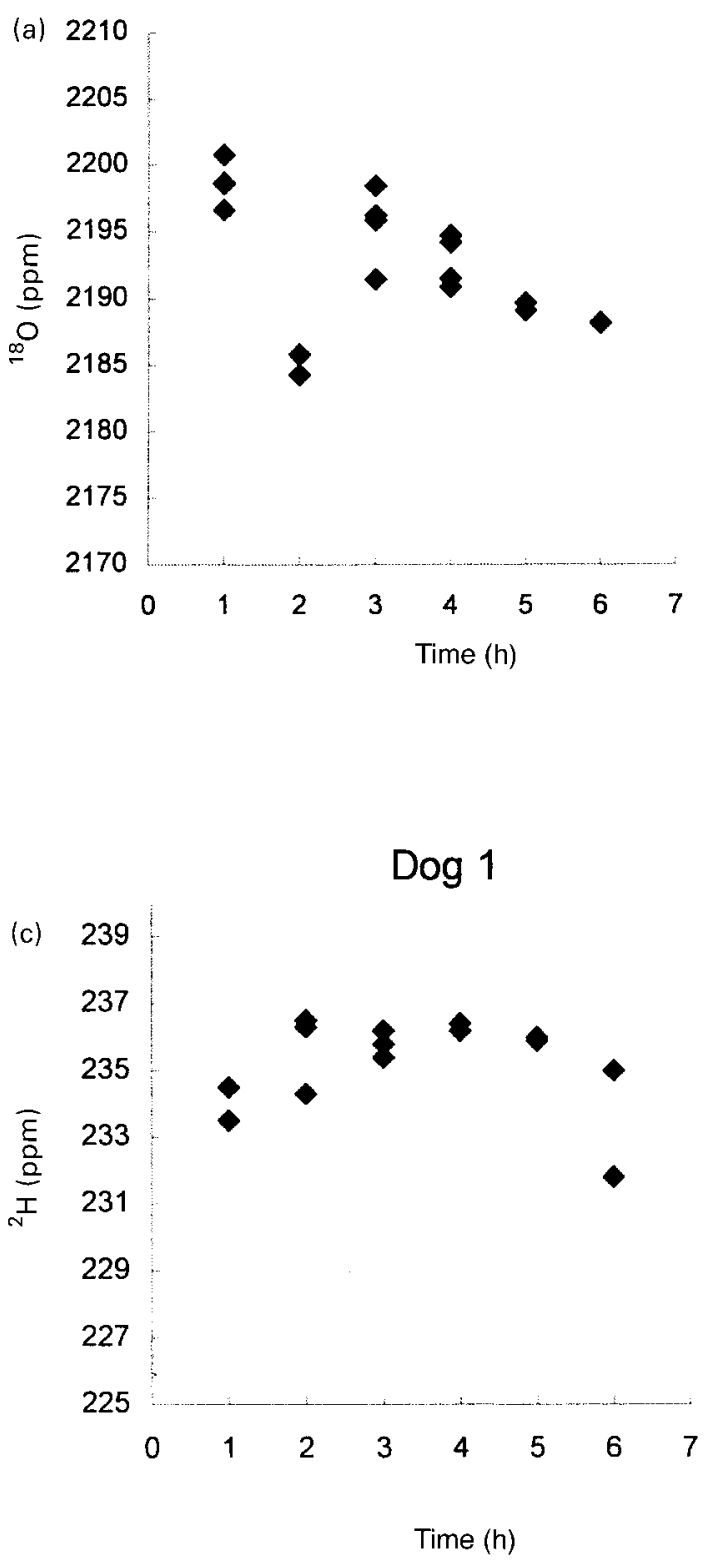

$\operatorname{Dog} 2$
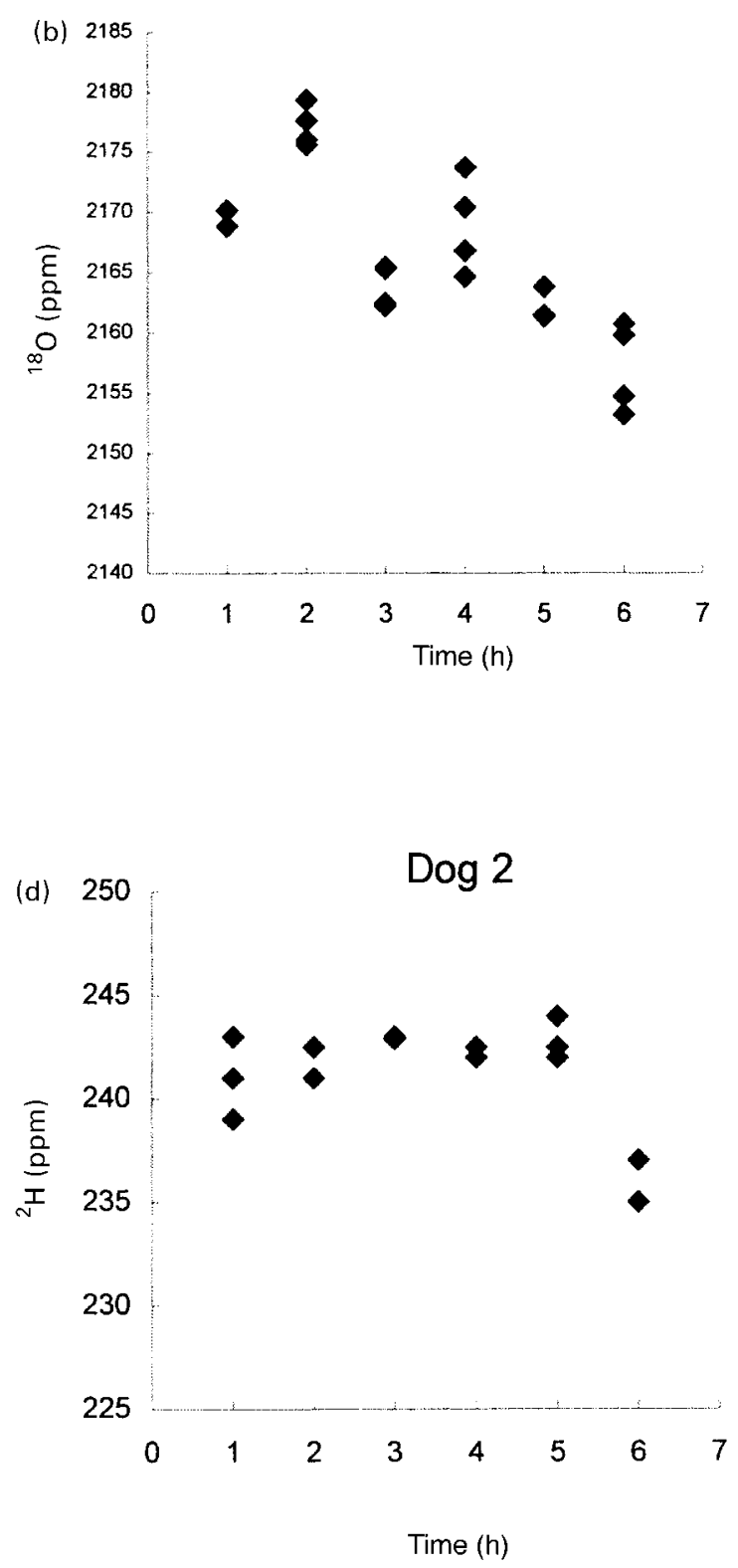

Fig. 2. Four examples of isotope equilibration but plotted at a finer scale. At this scale the isotope enrichments generally decreased between the first and sixth hours post-injection, compromising the interpretation from Fig. 1 that the isotopes had flooded into the dogs' entire exchangeable dilution space within the first hour post-injection.

\section{Results}

\section{Isotope equilibration and dilution spaces}

In all the dogs, except one, there was a rapid increase in the enrichments of both isotopes in the plasma water over the first hour post-injection. Thereafter, the enrichments of the isotopes appeared to be almost constant (e.g. Fig. 1(a)-(d)) but in reality were declining slightly (Fig. 2(a)-(d)). We averaged the observed isotope enrichments across the period from 1 to $6 \mathrm{~h}$ post-injection, and also took an average including only those determinations at the fifth and sixth hour. These calculations represented two alternative evaluations of the 'plateau' enrichment and were used to generate two 'plateau' dilution space estimates for each isotope (Table 1). We also predicted the enrichments at the time of injection by back extrapolation of the isotope elimination curves to time 0 . These curves included the equilibration data generated at 5 and $6 \mathrm{~h}$ post-injection, and all the subsequent daily samples (Table 1).

\section{Dilution space ratio}

Since we used three different techniques to derive the dilution spaces (two plateau and one intercept method) this 
Table 1. Evaluations of the ${ }^{18} \mathrm{O}\left(\mathrm{N}_{\mathrm{o}}\right)$ and ${ }^{2} \mathrm{H}\left(\mathrm{N}_{\mathrm{d}}\right)$ dilution spaces in the bodies of eight Labrador dogs using three different techniques (Dilution spaces are expressed as mols and as the equivalent litres water)

\begin{tabular}{|c|c|c|c|c|c|c|}
\hline Dog no. & Method & $\mathrm{N}_{\mathrm{o}}(\mathrm{mol})$ & $\mathrm{N}_{\mathrm{o}}$ (litres) & $\mathrm{N}_{\mathrm{d}}(\mathrm{mol})$ & $\mathrm{N}_{\mathrm{d}}$ (litres) & $N_{d}: \Lambda$ \\
\hline \multirow[t]{3}{*}{1} & $P_{1-6}$ & $1127 \cdot 1$ & $20 \cdot 28$ & 1011.6 & $19 \cdot 83$ & 0.97 \\
\hline & $P_{56}$ & $1150 \cdot 2$ & $20 \cdot 70$ & $1176 \cdot 3$ & $21 \cdot 17$ & .02 \\
\hline & I & $1077 \cdot 6$ & $19 \cdot 39$ & $1006 \cdot 1$ & $18 \cdot 11$ & .93 \\
\hline \multirow[t]{3}{*}{2} & $P_{1-6}$ & $1084 \cdot 3$ & $19 \cdot 51$ & $1016 \cdot 1$ & $18 \cdot 29$ & . \\
\hline & & $1062 \cdot 8$ & $19 \cdot 13$ & $1066 \cdot 2$ & $19 \cdot 19$ & 1.0 \\
\hline & & $1055 \cdot 3$ & 18.99 & 985.9 & $17 \cdot 74$ & 0.93 \\
\hline \multirow[t]{3}{*}{3} & $P_{1-6}$ & $754 \cdot 9$ & $13 \cdot 58$ & $763 \cdot 7$ & $13 \cdot 75$ & 1.0 \\
\hline & & $751 \cdot 3$ & 13. & $810 \cdot 3$ & 14.58 & 1.0 \\
\hline & 1 & $719 \cdot 7$ & 12.95 & $723 \cdot 7$ & 13.03 & 1.0 \\
\hline \multirow[t]{3}{*}{4} & $P_{1-6}$ & 925.9 & $16 \cdot 66$ & 921.8 & 16.59 & 0.9 \\
\hline & & $922 \cdot 3$ & $16 \cdot 60$ & $1006 \cdot 9$ & $18 \cdot 13$ & \\
\hline & I & 883.3 & 15. & 7.5 & 8 & 1 \\
\hline \multirow[t]{3}{*}{5} & $P_{1-6}$ & $869 \cdot 5$ & $15 \cdot 65$ & $955 \cdot 1$ & $17 \cdot 19$ & $1.0 \varsigma$ \\
\hline & & $881 \cdot 6$ & $15 \cdot 87$ & $1003 \cdot 9$ & 18.07 & $1 \cdot 15$ \\
\hline & & $851 \cdot 7$ & $15 \cdot 33$ & $913 \cdot 8$ & $16 \cdot 45$ & 1.07 \\
\hline \multirow[t]{3}{*}{6} & $P_{1-6}$ & 871.9 & $15 \cdot 69$ & $862 \cdot 7$ & $15 \cdot 53$ & 0.98 \\
\hline & & $870 \cdot 6$ & $15 \cdot 67$ & $877 \cdot 3$ & $15 \cdot 79$ & 1.0 \\
\hline & 1 & $850 \cdot 2$ & 15 & 3 & & $1 \cdot$ \\
\hline \multirow[t]{3}{*}{7} & $P_{1-6}$ & $1132 \cdot 4$ & $20 \cdot 40$ & $1200 \cdot 7$ & $21 \cdot 61$ & 1.06 \\
\hline & & $1132 \cdot 1$ & $20 \cdot 38$ & $1200 \cdot 5$ & $21 \cdot 61$ & 1.06 \\
\hline & & $1077 \cdot 1$ & $19 \cdot 41$ & $990 \cdot 9$ & $17 \cdot 83$ & 0.9 \\
\hline \multirow{3}{*}{8} & $P_{1-6}$ & $845 \cdot 6$ & $15 \cdot 24$ & $877 \cdot 7$ & $15 \cdot 80$ & 1.0 \\
\hline & & $844 \cdot 9$ & & & & \\
\hline & & $862 \cdot 9$ & $15 \cdot 54$ & 925.4 & $16 \cdot 66$ & 1.07 \\
\hline
\end{tabular}

$P_{1-6}$, The plateau evaluation averaging isotope enrichments over the entire $6 \mathrm{~h}$ of equilibration; $\mathrm{P}_{56}$, the plateau technique using the average of the samples taken 5 and $6 \mathrm{~h}$ after equilibration; I, the estimate generated from the intercept enrichment back extrapolated to the time of injection from the elimination curves.

\section{Isotope elimination: multiple-sample calculations}

Example plots of elimination curves for ${ }^{18} \mathrm{O}$ and ${ }^{2} \mathrm{H}$ for two individuals are presented in Fig. 3. In all cases the logconverted isotope abundances above background enrichment were correlated with time, over the $4 \mathrm{~d}$ post-injection, with $\mathrm{r}^{2}$ values exceeding $96 \%$ (Table 2). Across individuals the mean ${ }^{18} \mathrm{O}_{2}$ elimination constant was $0 \cdot 005478 / \mathrm{h}$ and the mean ${ }^{2} \mathrm{H}$ elimination constant was $0 \cdot 003949 / \mathrm{h}$. Hence the ratio of elimination constants for ${ }^{18} \mathrm{O}$ and ${ }^{2} \mathrm{H}$ averaged $1 \cdot 387$.

\section{Isotope elimination: two-sample calculations}

We made four replicate analyses of the isotope enrichments at the $6 \mathrm{~h}$ equilibrium time point and at the end of the final session in the indirect calorimeter ( $96 \mathrm{~h}$ later). We used these analyses to generate estimates of the elimination constants for both isotopes using the two-point methodology (Lifson et al. 1955; Schoeller et al. 1986). The twosample elimination constants are presented in Table 2. On average there was a close correspondence between the elimination constants derived using multiple sampling throughout the $4 \mathrm{~d}$ and the more restricted initial and final sampling protocols. For ${ }^{18} \mathrm{O}$ elimination the average discrepancy between the techniques was $1.47 \%$ (range -6.5 to $+8.9 \%$ ) and for ${ }^{2} \mathrm{H}$ it was $0.72 \%$, but this average masked a larger range $(-16 \cdot 0$ to $+16.5 \%)$. The discrepancies for the two isotopes were not correlated across individuals thus the average discrepancy in $\mathrm{k}_{\mathrm{o}}-\mathrm{k}_{\mathrm{d}}$ was $5.1 \%$.

\section{$\mathrm{CO}_{2}$ production}

Production of $\mathrm{CO}_{2}$, calculated using the elimination constants derived from multiple sampling and five alternative calculation methods (Lifson \& McClintock, 1966; Coward et al. 1985; Schoeller et al. 1986; Speakman, 1993; Speakman et al. 1993) was compared to the simultaneous $\mathrm{CO}_{2}$ production measured using indirect calorimetry. We combined the five different calculation methods with the three different methods of evaluating pool sizes, to generate fifteen different DLW estimates of $\mathrm{CO}_{2}$ production for each individual (Table 3). In all cases we estimated the mean pool size over the experimental duration using the final mass and assuming the pool size as a proportion of mass remained stable between the initial and final sampling. For

Table 2. Elimination constants $(/ \mathrm{h})$ for ${ }^{18} \mathrm{O}\left(\mathrm{k}_{\mathrm{o}}\right)$ and ${ }^{2} \mathrm{H}\left(\mathrm{k}_{\mathrm{d}}\right)$ in the bodies of eight Labrador dogs derived from multiple regression fits to daily samples over the $4 \mathrm{~d}$ of calorimetry $\mathrm{k}_{\mathrm{o}}(\mathrm{MS})$ and $\mathrm{k}_{\mathrm{d}}(\mathrm{MS})$, and from two-sample (initial and final) estimates $k_{o}(2 s)$ and $k_{d}(2 s)$, with the elimination ratios $\left(k_{o}: k_{d}\right)$ for the multiple sampled constants. The $r^{2}$ from the regressions are also shown

\begin{tabular}{lccccccc}
\hline Dog no. & $\mathrm{k}_{\mathrm{o}}(\mathrm{MS})$ & $r^{2}$ & $\mathrm{k}_{\mathrm{o}}(2 \mathrm{~s})$ & $\mathrm{k}_{\mathrm{d}}(\mathrm{MS})$ & $r^{2}$ & $\mathrm{k}_{\mathrm{d}}(2 \mathrm{~s})$ & $\mathrm{k}_{\mathrm{o}}: \mathrm{k}_{\mathrm{d}}$ \\
\hline 1 & 0.0048628 & 0.975 & 0.005274 & 0.0034925 & 0.977 & 0.004051 & 1.39235 \\
2 & 0.0058368 & 0.967 & 0.005456 & 0.0042212 & 0.979 & 0.004376 & 1.38273 \\
3 & 0.0071415 & 0.986 & 0.007496 & 0.0050712 & 0.971 & 0.005289 & 1.40825 \\
4 & 0.0043000 & 0.982 & 0.004842 & 0.0026400 & 0.964 & 0.002855 & 1.62879 \\
5 & 0.0050212 & 0.980 & 0.005166 & 0.0038745 & 0.955 & 0.003816 & 1.29596 \\
6 & 0.0042528 & 0.987 & 0.004125 & 0.0028708 & 0.977 & 0.002397 & 1.48140 \\
7 & 0.0054300 & 0.988 & 0.005814 & 0.0041300 & 0.977 & 0.004135 & 1.31477 \\
8 & 0.0069850 & 0.979 & 0.006741 & 0.0052900 & 0.962 & 0.004900 & 1.32042 \\
\hline
\end{tabular}



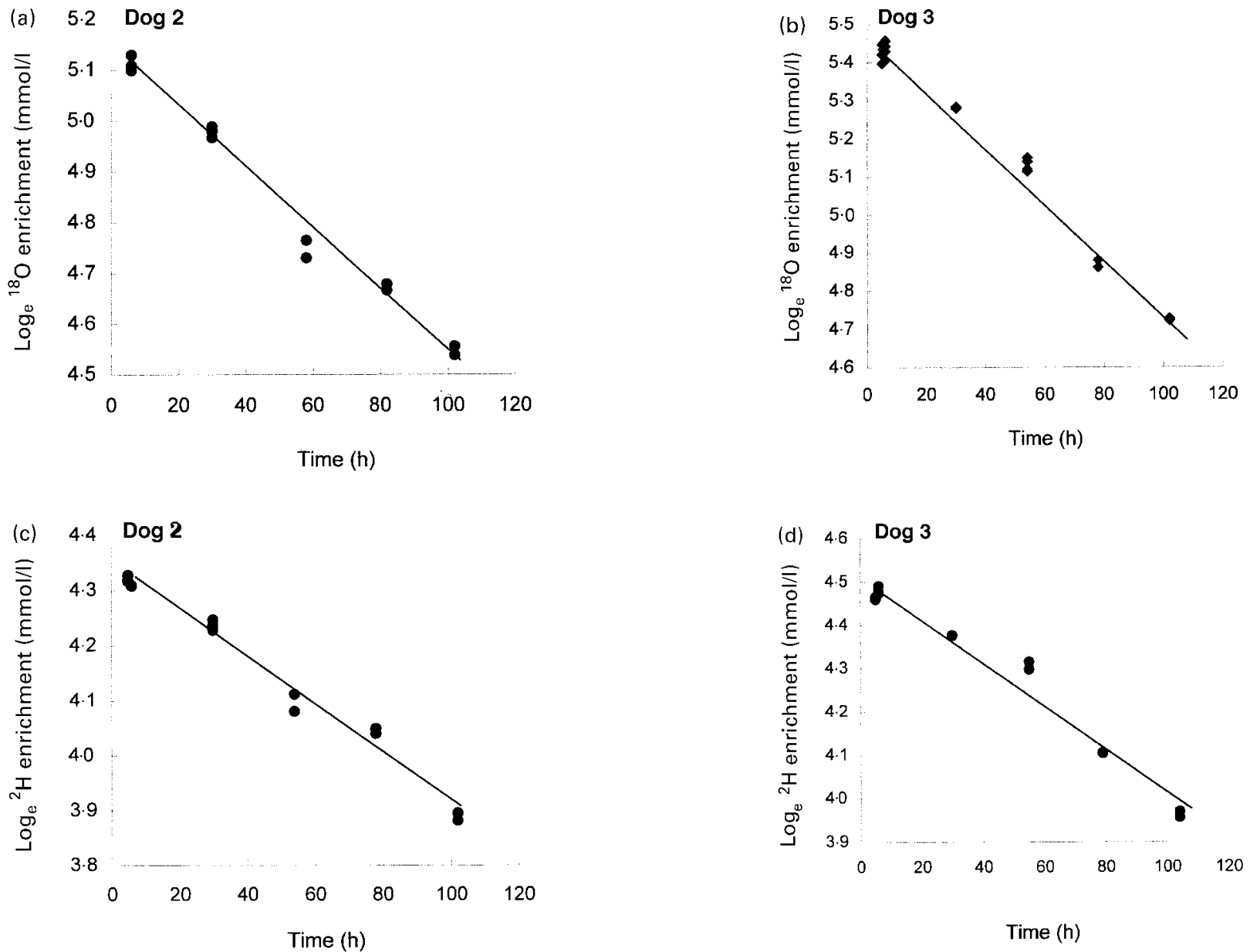

Fig. 3. Example plots of the log-converted isotope elimination curves for both isotopes for two dogs over the $4 \mathrm{~d}$ validation experiment. Note the ${ }^{18} \mathrm{O}$ enrichments are higher than the ${ }^{2} \mathrm{H}$ enrichments because more ${ }^{18} \mathrm{O}$ isotope is injected, and in both sets of figures the frequently observed temporal concordance in the deviations of both isotopes from the overall mean rate of decline. When the ${ }^{18} \mathrm{O}$ isotope evaluation is high relative to the fitted curve so is the ${ }^{2} \mathrm{H}$ and vice versa.

each calculation we determined the empirical precision of the resultant estimate using a multiple sample equivalent of the jacknife procedure (Speakman, 1995). This procedure quantifies the analytical precision of the DLW estimate expressed as a CV (\%). This precision estimate along with the percentage deviations of the DLW results from the indirect calorimetry results are also presented in Table 3 . The original method of calculation advocated by Lifson \& McClintock (1966; single-pool model) resulted in an overestimate of the $\mathrm{CO}_{2}$ production in all the animals. The overestimate varied from $17.9 \%$ for $\operatorname{dog} 6$ to $81.1 \%$ for $\operatorname{dog} 4$ (mean $42.4 \%$ ). There was no significant effect of the method of calculating the dilution space on the average error (ANOVA; $F \quad 0 \cdot 19, P>0.05$ ). The analytical precision, by jacknife, using this equation averaged $4.5 \%$.

When using the equation advocated by Coward et al. (1985; two-pool model using individual ratios for dilution space) the technique also tended to overestimate $\mathrm{CO}_{2}$ production. The errors ranged from $-25.8 \%$ to $+80.0 \%$ and the mean overestimate was $30 \cdot 0 \%$. Although the mean error using this method (accuracy) was closer to the direct measurement than the estimate using the Lifson model, the mean deviation (precision) was worse. Analytical precision averaged 5.5\%. Equation A6 of Schoeller et al. (1986; two-pool model using fixed estimate for dilution space ratio of 1.03) also generally overestimated the simultaneously measured $\mathrm{CO}_{2}$ production. The errors varied between $+10.3 \%$ for $\operatorname{dog} 6$ and $+72.0 \%$ for $\operatorname{dog} 4$, with a mean error of $37.2 \%$. Analytical precision using this equation averaged $4.6 \%$. It has been suggested that the fixed ratio used in the equation derived by Schoeller et al. (1986) may have been too small and a new equation was derived utilising more recent data (Speakman et al. 1993). Following this paper there has been much debate over the actual fixed ratio which should be employed in these studies and the validity of the revised estimate (Coward et al. 1994; Racette et al. 1994). Using the revised equation the DLW technique overestimated the $\mathrm{CO}_{2}$ production by between $6.6 \%(\operatorname{dog} 6)$ and $67.2 \%(\operatorname{dog} 4)$ with an average error of $29.1 \%$. Analytical precision for this calculation averaged $4.8 \%$. These latter two methods use fixed ratios inferred from populations of humans which may not be appropriate for dogs. An alternative approach is to use the observed group mean dilution space ratio (Speakman, 
Table 3. Calculations of carbon dioxde production for eight Labrador dogs using five different calculation methods (a-e)* with three different methods for evaluation of the dilution space (two plateau estimates, $P_{1-6}$ and $P_{56}$, and the intercept, I) and the elimination constants derived from multipoint sampling throughout the $4 \mathrm{~d}$ of elimination, in comparison to the indirect calorimetric evaluations over the same periods

(For the five alternative calculation methods employed, the absolute and \% err values were calculated for each)

\begin{tabular}{|c|c|c|c|c|c|c|c|c|c|c|c|c|}
\hline \multirow[b]{2}{*}{ Dog no. } & \multirow[b]{2}{*}{ Pool } & \multirow[b]{2}{*}{ IC $(\mathrm{I} / \mathrm{h})$} & \multicolumn{10}{|c|}{ DLW estimates } \\
\hline & & & $a$ & \%err & $\mathrm{b}$ & \%err & c & \%err & d & $\%$ err & e & \%err \\
\hline \multirow[t]{4}{*}{1} & $P_{1-6}$ & $12 \cdot 00$ & $15 \cdot 31$ & $27 \cdot 6$ & $16 \cdot 31$ & 35.9 & $14 \cdot 19$ & $18 \cdot 2$ & $13 \cdot 60$ & $13 \cdot 3$ & 12.97 & 7.49 \\
\hline & $P_{56}$ & $12 \cdot 00$ & $15 \cdot 62$ & $30 \cdot 2$ & $14 \cdot 62$ & 21.9 & $14 \cdot 80$ & 23.4 & $14 \cdot 19$ & $18 \cdot 2$ & 13.50 & $11 \cdot 12$ \\
\hline & I & $12 \cdot 00$ & 14.64 & $22 \cdot 0$ & $17 \cdot 43$ & $45 \cdot 2$ & $13 \cdot 27$ & $10 \cdot 6$ & $12 \cdot 72$ & 6.01 & $12 \cdot 16$ & 1.33 \\
\hline & AP & & & 6.5 & & $13 \cdot 1$ & & 6.5 & & $6 \cdot 9$ & & 5.9 \\
\hline \multirow[t]{4}{*}{2} & $P_{1-6}$ & $10 \cdot 65$ & $17 \cdot 32$ & $62 \cdot 7$ & $20 \cdot 55$ & $92 \cdot 9$ & $15 \cdot 74$ & $47 \cdot 8$ & $15 \cdot 07$ & 41.5 & $14 \cdot 36$ & $25 \cdot 86$ \\
\hline & $P_{56}$ & $10 \cdot 65$ & 16.98 & 59.5 & $16 \cdot 84$ & $58 \cdot 1$ & 15.94 & 49.7 & $15 \cdot 26$ & $43 \cdot 3$ & 14.50 & 26.53 \\
\hline & 1 & $10 \cdot 65$ & $16 \cdot 86$ & $58 \cdot 3$ & $20 \cdot 14$ & $89 \cdot 1$ & $15 \cdot 29$ & $43 \cdot 6$ & 14.64 & 37.5 & 13.96 & 23.73 \\
\hline & AP & & & $6 \cdot 2$ & & $2 \cdot 4$ & & $6 \cdot 2$ & & $6 \cdot 8$ & & 5.5 \\
\hline \multirow[t]{4}{*}{3} & $P_{1-6}$ & $10 \cdot 84$ & 15.54 & 43.4 & $15 \cdot 06$ & 39.0 & 14.65 & $35 \cdot 1$ & 14.06 & $29 \cdot 7$ & 13.45 & $19 \cdot 41$ \\
\hline & $P_{56}$ & $10 \cdot 84$ & $15 \cdot 46$ & $42 \cdot 7$ & $12 \cdot 16$ & $12 \cdot 1$ & $15 \cdot 06$ & 38.9 & 14.45 & 33.3 & $13 \cdot 77$ & $21 \cdot 33$ \\
\hline & 1 & $10 \cdot 84$ & 14.82 & $36 \cdot 7$ & $14 \cdot 61$ & $34 \cdot 8$ & $15 \cdot 87$ & $85 \cdot 8$ & $13 \cdot 36$ & $23 \cdot 3$ & $12 \cdot 79$ & $15 \cdot 25$ \\
\hline & AP & & & $2 \cdot 1$ & & 2.4 & & $2 \cdot 2$ & & $2 \cdot 3$ & & 1.9 \\
\hline \multirow[t]{4}{*}{4} & $P_{1-6}$ & 8.54 & $15 \cdot 73$ & 84.2 & $13 \cdot 20$ & 54.6 & 14.69 & $72 \cdot 0$ & 14.28 & $67 \cdot 2$ & $14 \cdot 20$ & 39.87 \\
\hline & $P_{56}$ & 8.54 & $5 \cdot 67$ & 83.5 & 14.90 & 74.46 & $15 \cdot 32$ & $79 \cdot 4$ & 14.90 & 74.4 & 14.77 & $42 \cdot 19$ \\
\hline & 1 & $8 \cdot 54$ & $15 \cdot 00$ & $75 \cdot 7$ & 13.92 & 28.4 & 14.07 & $64 \cdot 8$ & $13 \cdot 68$ & $60 \cdot 2$ & $13 \cdot 60$ & $37 \cdot 23$ \\
\hline & AP & & & $2 \cdot 6$ & & $2 \cdot 5$ & & $2 \cdot 9$ & & 3.0 & & $2 \cdot 6$ \\
\hline \multirow[t]{4}{*}{5} & $P_{1-6}$ & $7 \cdot 71$ & $9 \cdot 60$ & $24 \cdot 6$ & 5.93 & $-23 \cdot 1$ & 9.45 & $22 \cdot 6$ & 8.93 & $15 \cdot 8$ & $8 \cdot 10$ & 4.87 \\
\hline & $P_{56}$ & $7 \cdot 71$ & $9 \cdot 73$ & $26 \cdot 3$ & 4.48 & -41.9 & $9 \cdot 76$ & $26 \cdot 6$ & $9 \cdot 23$ & $19 \cdot 7$ & 8.35 & $7 \cdot 66$ \\
\hline & 1 & $7 \cdot 71$ & 9.40 & $22 \cdot 0$ & $6 \cdot 73$ & -12.5 & $9 \cdot 15$ & $18 \cdot 6$ & $8 \cdot 64$ & $12 \cdot 1$ & $7 \cdot 85$ & 1.89 \\
\hline & AP & & & $7 \cdot 2$ & & $11 \cdot 3$ & & $7 \cdot 2$ & & 7.4 & & $6 \cdot 3$ \\
\hline \multirow[t]{4}{*}{6} & $P_{1-6}$ & $10 \cdot 20$ & $12 \cdot 13$ & $19 \cdot 0$ & $12 \cdot 44$ & $22 \cdot 0$ & $11 \cdot 30$ & $10 \cdot 8$ & $10 \cdot 91$ & $7 \cdot 01$ & $10 \cdot 63$ & 4.05 \\
\hline & $P_{56}$ & $10 \cdot 20$ & $12 \cdot 11$ & $18 \cdot 8$ & 11.92 & $16 \cdot 85$ & 11.39 & $11 \cdot 6$ & 10.99 & $7 \cdot 82$ & $10 \cdot 70$ & $4 \cdot 70$ \\
\hline & I & $10 \cdot 20$ & 11.83 & $16 \cdot 0$ & 11.78 & 15.45 & 11.09 & 8.7 & $10 \cdot 71$ & 5.02 & $10 \cdot 42$ & $2 \cdot 17$ \\
\hline & AP & & & 4.3 & & $5 \cdot 8$ & & 4.4 & & 4.6 & & $4 \cdot 1$ \\
\hline \multirow[t]{4}{*}{7} & $P_{1-6}$ & 11.14 & 14.28 & 28.2 & $11 \cdot 16$ & 0.20 & $13 \cdot 80$ & 23.8 & 13.08 & $17 \cdot 4$ & $12 \cdot 03$ & 7.44 \\
\hline & $P_{56}$ & $11 \cdot 14$ & 14.27 & $28 \cdot 2$ & $11 \cdot 15$ & 0.13 & $13 \cdot 79$ & $23 \cdot 8$ & 13.08 & $17 \cdot 4$ & $12 \cdot 03$ & 7.42 \\
\hline & I & $11 \cdot 14$ & 13.58 & 21.9 & 17.55 & 57.59 & $12 \cdot 24$ & $9 \cdot 9$ & 11.61 & 4.29 & 10.78 & -3.24 \\
\hline & AP & & & 5.5 & & $5 \cdot 0$ & & $5 \cdot 8$ & & 5.9 & & $5 \cdot 3$ \\
\hline \multirow[t]{4}{*}{8} & $P_{1-6}$ & $8 \cdot 66$ & 13.93 & $60 \cdot 9$ & $12 \cdot 06$ & 39.24 & $13 \cdot 31$ & 53.7 & $12 \cdot 64$ & $45 \cdot 9$ & 11.67 & $25 \cdot 84$ \\
\hline & $P_{56}$ & $8 \cdot 66$ & 13.92 & $60 \cdot 7$ & 11.95 & 37.97 & $13 \cdot 32$ & $53 \cdot 8$ & $12 \cdot 64$ & $46 \cdot 0$ & 11.67 & $25 \cdot 84$ \\
\hline & 1 & 8.66 & 14.21 & $64 \cdot 2$ & $10 \cdot 56$ & 21.93 & $13 \cdot 81$ & 59.5 & $13 \cdot 11$ & 51.4 & $12 \cdot 08$ & $28 \cdot 35$ \\
\hline & AP & & & $1 \cdot 7$ & & $2 \cdot 0$ & & 1.6 & & 1.7 & & 1.6 \\
\hline
\end{tabular}

DLW, doubly-labelled water evaluations; IC, indirect calorimetric evaluation; \%err, difference divided by IC multiplied by 100; AP, analytical precision error calculated as CV (\%) derived from a multiple sample equivalent of jacknife procedure described in Speakman (1995).

* The five methods were: a, Lifson \& McClintock (1966) 36 single-pool model; b, Coward et al. (1985) two-pool model, individual pool size ratios used; c, Schoeller et al. (1986) equation A6, two-pool model, fixed pool size ratio at 1.03; d, Speakman et al. (1993) two-pool model, fixed dilution space ratio at 1.0432; e, Speakman (1993) two-pool model using observed pool size ratio at 1.0554.

Table 4. Food intake $(\mathrm{kg})$ of eight Labrador dogs throughout a $4 \mathrm{~d}$ validation of the doubly-labelled water technique and their mass changes (mch) along with the inferred energy expenditure from the metabolisable energy intake and mass balance under three different limiting assumptions for the nature of the mass change: that all the mass change is water (1); that the mass is partly water and partly fat (2); the mass is partly water and partly protein (3) (see p. 77 for full details on proportions and energy equivalents)

\begin{tabular}{|c|c|c|c|c|c|c|c|c|c|}
\hline \multirow[b]{2}{*}{ Dog no. } & \multirow{2}{*}{$\begin{array}{l}\text { Food intake } \\
\qquad(\mathrm{kg})\end{array}$} & \multirow{2}{*}{$\begin{array}{l}\mathrm{mch} \\
(\mathrm{kg})\end{array}$} & \multirow{2}{*}{$\begin{array}{l}\text { El } \\
(\mathrm{kJ})\end{array}$} & \multirow{2}{*}{$\begin{array}{c}\text { El } \\
(\mathrm{kJ} / \mathrm{h})\end{array}$} & \multicolumn{3}{|c|}{$\mathrm{CO}_{2}$ production $(\mathrm{l} / \mathrm{h})^{*}$ by method: } & \multirow[b]{2}{*}{ Cal } & \multirow{2}{*}{$\begin{array}{l}\text { Difference in estimated } \\
\text { levels of } \mathrm{CO}_{2} \text { production } \\
(\mathrm{Cal}-\mathrm{EI})\end{array}$} \\
\hline & & & & & 1 & 2 & 3 & & \\
\hline 1 & $2 \cdot 612$ & -0.400 & 37613 & $365 \cdot 2$ & 14.54 & $16 \cdot 19$ & $15 \cdot 32$ & 12.00 & 2.54 \\
\hline 2 & $2 \cdot 806$ & 0.100 & 40406 & 392.3 & $15 \cdot 62$ & $15 \cdot 14$ & $15 \cdot 39$ & $10 \cdot 65$ & 4.97 \\
\hline 3 & 1.452 & -0.717 & 20909 & 203.0 & 8.08 & 12.90 & $10 \cdot 37$ & $10 \cdot 84$ & -2.75 \\
\hline 4 & 1.880 & 0.080 & 27072 & $262 \cdot 8$ & $10 \cdot 47$ & 9.98 & $10 \cdot 24$ & 8.54 & 1.92 \\
\hline 5 & 1.800 & 0.680 & 25920 & 251.6 & $10 \cdot 02$ & 4.98 & 7.62 & $7 \cdot 71$ & $2 \cdot 31$ \\
\hline 6 & 2.000 & -0.170 & 28800 & $279 \cdot 6$ & $11 \cdot 13$ & 12.43 & 11.75 & $10 \cdot 20$ & 0.93 \\
\hline 7 & 2.370 & 0.298 & 34128 & 331.3 & $13 \cdot 19$ & 11.34 & $12 \cdot 31$ & $11 \cdot 14$ & 2.05 \\
\hline 8 & 1.791 & 0.647 & 25790 & 250.4 & 9.97 & $5 \cdot 72$ & 7.95 & 8.66 & 1.31 \\
\hline
\end{tabular}

$\mathrm{EI}$, energy intake, using metabolisable energy intake for diet of $14.5 \mathrm{~kJ} / \mathrm{g}$; Cal, the directly evaluated $\mathrm{CO}_{2}$ production by indirect calorimetry

* The equivalent $\mathrm{CO}_{2}$ production for the corresponding levels of expenditure calculated using $R Q$. 
1993). The estimated $\mathrm{CO}_{2}$ production using this latter method varied from $+3.6 \%(\operatorname{dog} 7)$ to $+39.8 \%(\operatorname{dog} 4)$ and averaged $16.2 \%$ bigger. The analytical precision in this case was $4.1 \%$. There was no correlation between individual deviations between DLW and calorimetry and the analytical precision of the determinations for that particular animal.

We recalculated $\mathrm{CO}_{2}$ production using the two-sample derived estimates of the elimination constants combined with the plateau pool size estimate at 5 and $6 \mathrm{~h}$. Because the difference between the elimination constants derived from the two-sample approach were on average slightly greater than the multiple sample approach, the derived estimates of $\mathrm{CO}_{2}$ production were also greater, which generally worsened the comparison to the indirect calorimetric evaluation (Table 3). On average the Lifson \& McClintock (1966) equation overestimated $\mathrm{CO}_{2}$ production by $66.9 \%$, the Coward et al. (1985) equation by $41.1 \%$, the Schoeller et al. (1986) equation by $50.9 \%$, the Speakman et al. (1993) equation by $44.4 \%$ and the Speakman (1993) equation by $27.7 \%$. Mean deviation was not improved compared with the results from multiple sampling, suggesting individual differences between the two sample approach and multiple sampling were the consequence of random errors. Analytical precision by jacknife, using the two-sample approach, averaged 2-3\% worse than when using the multiple sampling method, as would be anticipated from the reduced sample size of determinations.

\section{Food intake and mass balance}

Food intakes and body mass changes of the animals over the $4 \mathrm{~d}$ trial are presented in Table 4 . Five of the dogs gained mass and three lost mass during the experimental period. The maximum mass loss was $0.717 \mathrm{~kg}$ and the maximum gain was $0.647 \mathrm{~kg}$. Across individuals the average mass change was only $65 \mathrm{~g}$. Food intake varied between 1.45 and $2.8 \mathrm{~kg}$ during the $4 \mathrm{~d}$, and averaged $2.09 \mathrm{~kg}$. Food intake and mass change were not correlated $\left(r^{2} 0 \cdot 12\right)$. We converted the food intake into energy intake using the established metabolisable energy content of this diet of $14.54 \mathrm{~kJ} / \mathrm{g}$. To convert the mass change into energy changes we made three different assumptions. First, we assumed that all the mass changes reported were actually changes only in hydration and no energy was withdrawn or stored (method 1). Second, we assumed that the water content of the body tissues evaluated at the start of the experiments from the ${ }^{18} \mathrm{O}$ isotope dilution was maintained throughout the $4 \mathrm{~d}$ period. Hence this was also the water content of the mass that had been lost or gained over the $4 \mathrm{~d}$. Using these estimates we calculated the amount of dry tissue that each animal lost or gained over the validation period. We converted this dry mass into energy using two limiting assumptions for the nature of this dry tissue. We assumed it was all protein with an energy content of $18.0 \mathrm{~kJ} / \mathrm{g}$ (method 2) or we assumed it was all fat, with an energy content of $39.6 \mathrm{~kJ} / \mathrm{g}$ (method 3). Energy contents were taken from Schmidt-Nielsen (1975). Using these two assumed energy contents we estimated the energy content of the dry body mass change of the animals and added this to the energy derived from food. The energy expenditures for all three methods were then converted into $\mathrm{CO}_{2}$ production using the average RQ for that animal.

Comparison of the DLW estimates of $\mathrm{CO}_{2}$ production to those derived from food intake revealed a closer correspondence than was found between DLW and indirect calorimetry (Table 5). On average (across all individuals and methods of estimating the dilution spaces) the Lifson \& McClintock (1966) equation resulted in values which overestimated the $\mathrm{CO}_{2}$ production based on food intakemass balance by, on average, $+23.7 \%,+42.2 \%$ and $+28.3 \%$ for the three methods (water, fat and protein assumptions) respectively. Using the Coward et al. (1985) equation the mean comparison to food intake-mass balance averaged $+16.1 \%,+25.5 \%$ and $+16.9 \%$, the Schoeller et al. (1986) equation A6 resulted in average differences of $+19.3 \%,+35.7 \%$ and $+19.5 \%$, the equation of Speakman et al. (1993) gave average discrepancies of $+13.5 \%$, $+29.4 \%$ and $+16.5 \%$ and using the observed group mean dilution space ratio (Speakman, 1993) gave mean discrepancies of $+8.0 \%,+22.2 \%$ and $+10.5 \%$.

\section{Discussion}

\section{Isotope equilibration and dilution spaces}

The pattern of variation in isotope enrichment during the $6 \mathrm{~h}$ immediately post-injection (Figs. 1 and 2) suggested that the isotopes flooded rapidly into the plasma pool of the animal immediately following the intravenous injection, and thereafter slowly pervaded less-accessible pools (Matthews \& Gilker, 1995). The decline in isotope enrichment observed over the period from 2 to $6 \mathrm{~h}$ reflected the slow perfusion of these other body pools.

\section{Dilution space ratio}

In contrast with reviews of dilution space estimates across studies of humans, which have suggested the dilution space ratio does not depend on technique (plateau or intercept) (Speakman et al. 1993; Coward et al. 1994; Racette et al. 1994), we found technique did have a large effect in dogs. In theory, because the lines for the oxygen and hydrogen elimination have different slopes, one would expect their convergence (or divergence), as one neared the intercept, would lead to a change in the dilution space ratio (G. H. Visser, personal communication). Thus, our observations are more consistent with the expectation from theory. Several previous studies (e.g. Wong et al. 1988), however, have also found little evidence that the method affects the derived ratio, contrasting the present findings. The reasons for the failure of these studies to detect a technique-based effect are less clear. However, all previous comparisons of the dilution space ratio measured at intercept and plateau have involved studies of humans where the dosing and sampling protocols differ significantly from that employed in the present study. In particular, previous studies of humans have generally involved oral dosing and sampling of urine to establish the pattern of equilibration, although some studies have employed a range of different sources of body water (Schoeller et al. 1980; Wong et al. 1988). Oral 
Table 5. Percentage differences between food intake-mass balance evaluations of $\mathrm{CO}_{2}$ production using three alternative methods*

\begin{tabular}{|c|c|c|c|c|c|c|c|c|c|c|c|c|c|c|c|c|}
\hline \multirow[b]{2}{*}{ Dog no. } & \multirow[b]{2}{*}{ Technique } & \multicolumn{3}{|c|}{$\begin{array}{l}\text { Lifson \& McClintock } \\
\qquad(1966)\end{array}$} & \multicolumn{3}{|c|}{$\begin{array}{l}\text { Coward et al. } \\
\text { (1985) }\end{array}$} & \multicolumn{3}{|c|}{$\begin{array}{c}\text { Schoeller et al. } \\
\text { (1986) (equation A6) }\end{array}$} & \multicolumn{3}{|c|}{$\begin{array}{c}\text { Speakman et al. } \\
\text { (1993) }\end{array}$} & \multicolumn{3}{|c|}{$\begin{array}{l}\text { Speakman } \\
(1993)\end{array}$} \\
\hline & & 1 & 2 & 3 & 1 & 2 & 3 & 1 & 2 & 3 & 1 & 2 & 3 & 1 & 2 & 3 \\
\hline & $1-6$ & & 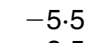 & -0 . & $12 \cdot 1$ & 0.7 & - & $2 \cdot 4$ & 4 & -7.4 & $-6 \cdot 4$ & $-16 \cdot 0$ & $-4 \cdot 6$ & $-10 \cdot 8$ & -19.8 & $-15 \cdot 3$ \\
\hline & & & - & 1. & 0.5 & $-9 \cdot 7$ & $-11 \cdot 2$ & $1 \cdot 8$ & $-8 \cdot 6$ & -3.4 & -2.4 & $-12 \cdot 3$ & $13 \cdot 7$ & $-7 \cdot 1$ & $-16 \cdot 7$ & -11.9 \\
\hline & I & 0 . & $-9 \cdot 6$ & -4.4 & $19 \cdot 8$ & $7 \cdot 6$ & -7.4 & -8.7 & -18.0 & $6 \cdot 4$ & -12.5 & -21.4 & $-16 \cdot 9$ & $-16 \cdot 3$ & -24.9 & $-20 \cdot 6$ \\
\hline \multirow[t]{3}{*}{2} & $P_{1-6}$ & $10 \cdot 8$ & $14 \cdot 3$ & 12.5 & 31.5 & $35 \cdot 6$ & 33.4 & $-5 \cdot 6$ & $-2 \cdot 6$ & $-4 \cdot 2$ & -3.5 & -0.4 & $-2 \cdot 1$ & -8.0 & $-5 \cdot 2$ & -6.7 \\
\hline & & $8 \cdot 6$ & 12. & $10 \cdot 3$ & $7 \cdot 8$ & $11 \cdot 2$ & $9 \cdot 4$ & $2 \cdot 0$ & 5 & 3.5 & $-2 \cdot 3$ & 0.7 & -0.8 & $-7 \cdot 1$ & $-4 \cdot 2$ & $-5 \cdot 8$ \\
\hline & 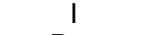 & 7 & 11 & 9. & 28.9 & 33. & $30 \cdot 8$ & $-2 \cdot 1$ & 0 & -0.6 & $-6 \cdot 2$ & -3.3 & $-4 \cdot 9$ & $-10 \cdot 6$ & $-7 \cdot 8$ & $-9 \cdot 3$ \\
\hline \multirow[t]{3}{*}{3} & $P_{1-6}$ & $92 \cdot 2$ & $20 \cdot 4$ & $49 \cdot 2$ & $86 \cdot 2$ & $16 \cdot 7$ & $45 \cdot 2$ & $81 \cdot 2$ & 13.5 & $41 \cdot 2$ & 73.9 & 8.9 & 35.5 & 3 & $4 \cdot 2$ & $29 \cdot 6$ \\
\hline & & 9 & 19 & 49. & 87.5 & 17. & $46 \cdot 2$ & $86 \cdot 2$ & 16 & 45 & $78 \cdot 7$ & 12 & $39 \cdot 3$ & . 3 & 7 & 32.7 \\
\hline & 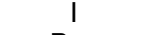 & 83.3 & $14 \cdot 8$ & $42 \cdot 8$ & 80.7 & $13 \cdot 2$ & $40 \cdot 8$ & $96 \cdot 3$ & 23. & 53.0 & $65 \cdot 2$ & 3.5 & $28 \cdot 8$ & $58 \cdot 2$ & -0.8 & 23.3 \\
\hline \multirow[t]{3}{*}{ 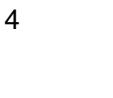 } & $P_{1-6}$ & $50 \cdot 2$ & 57.5 & $53 \cdot 6$ & $26 \cdot 1$ & $32 \cdot 2$ & 28.9 & $40 \cdot 3$ & $47 \cdot 1$ & 43.4 & $36 \cdot 4$ & 43.0 & 39.4 & 35.6 & $42 \cdot 2$ & 38.6 \\
\hline & & $50 \cdot 2$ & 57.5 & $53 \cdot 6$ & $42 \cdot 3$ & $49 \cdot 2$ & $45 \cdot 5$ & $46 \cdot 3$ & 53.4 & $49 \cdot 6$ & $42 \cdot 3$ & $49 \cdot 2$ & $45 \cdot 5$ & 41.1 & $47 \cdot 9$ & 44.2 \\
\hline & 1 & 4 & 50 & 46.5 & 32.9 & 39.4 & 9 & 34.4 & & 37.4 & $30 \cdot 6$ & 37 & $33 \cdot 6$ & .2 & 2 & $32 \cdot 8$ \\
\hline \multirow[t]{3}{*}{5} & $\mathrm{P}_{1-6}$ & $-4 \cdot 2$ & $92 \cdot 6$ & 27.5 & $-40 \cdot 8$ & $19 \cdot 0$ & $-22 \cdot 2$ & $-5 \cdot 7$ & 89.6 & 23.9 & $-10 \cdot 8$ & $79 \cdot 2$ & $17 \cdot 0$ & $-19 \cdot 1$ & $62 \cdot 3$ & $6 \cdot 1$ \\
\hline & $P_{56}$ & -2.9 & $95 \cdot 2$ & 27.5 & -55.3 & $-10 \cdot 0$ & $-41 \cdot 8$ & -2.6 & $95 \cdot 8$ & $27 \cdot 9$ & -7.9 & $85 \cdot 2$ & $21 \cdot 0$ & $-16 \cdot 7$ & $67 \cdot 6$ & 9.4 \\
\hline & & $-6 \cdot 2$ & $88 \cdot 7$ & $23 \cdot 2$ & $-32 \cdot 8$ & $35 \cdot 1$ & -11.7 & $-8 \cdot 7$ & 83.6 & 19.9 & $-13 \cdot 7$ & $73 \cdot 4$ & $13 \cdot 2$ & $-21 \cdot 7$ & 57.5 & 2.9 \\
\hline \multirow[t]{3}{*}{6} & $P_{1-6}$ & $8 \cdot 9$ & $-2 \cdot 4$ & $3 \cdot 2$ & 11.7 & 0.06 & $5 \cdot 9$ & 1.5 & $-9 \cdot 1$ & -3.8 & $-2 \cdot 0$ & $-12 \cdot 2$ & $-7 \cdot 1$ & -4.5 & -14.5 & -9.5 \\
\hline & & & -2.5 & 3.0 & $7 \cdot 0$ & $-4 \cdot 1$ & 1.4 & $2 \cdot 3$ & $-8 \cdot 3$ & -3.0 & $-1 \cdot 3$ & -11.5 & $-6 \cdot 4$ & -3.9 & $-13 \cdot 9$ & -8.9 \\
\hline & 1 & 6 & $-4 \cdot 8$ & 0.6 & $5 \cdot 8$ & $-5 \cdot 2$ & 0.2 & -0.4 & $-10 \cdot 8$ & $-5 \cdot 6$ & $-3 \cdot 8$ & $-13 \cdot 8$ & $-8 \cdot 8$ & $-6 \cdot 4$ & $-16 \cdot 1$ & -11.3 \\
\hline \multirow[t]{3}{*}{1} & $P_{1-6}$ & $8 \cdot 2$ & $25 \cdot 9$ & $15 \cdot 9$ & -15.4 & -1.6 & $-9 \cdot 3$ & $4 \cdot 6$ & $21 \cdot 7$ & $12 \cdot 1$ & -0.8 & $15 \cdot 3$ & $6 \cdot 2$ & $-8 \cdot 8$ & $6 \cdot 1$ & $-2 \cdot 3$ \\
\hline & & $8 \cdot 1$ & $25 \cdot 8$ & 15.9 & -15.5 & $-1 \cdot 7$ & -9.4 & 4.5 & $21 \cdot 6$ & $12 \cdot 0$ & -0.8 & $15 \cdot 3$ & $6 \cdot 2$ & $-8 \cdot 8$ & $6 \cdot 1$ & $-2 \cdot 3$ \\
\hline & & $\cdot 9$ & $19 \cdot 8$ & $10 \cdot 3$ & $32 \cdot 9$ & $54 \cdot 7$ & 42.5 & $-7 \cdot 2$ & 7.9 & -0.6 & $-18 \cdot 3$ & $2 \cdot 4$ & -5.7 & $-18 \cdot 3$ & -4.9 & -12.5 \\
\hline \multirow[t]{3}{*}{8} & $P_{1-6}$ & 39.6 & 143.4 & $75 \cdot 1$ & 20.9 & $110 \cdot 7$ & $51 \cdot 6$ & 33.4 & $132 \cdot 6$ & $67 \cdot 3$ & $26 \cdot 7$ & $120 \cdot 9$ & 58.9 & $17 \cdot 0$ & 103.9 & $46 \cdot 7$ \\
\hline & & 39.5 & & $75 \cdot 0$ & $5 \cdot 9$ & 84 & $32 \cdot 7$ & 33.5 & $132 \cdot 7$ & 67.5 & $26 \cdot 7$ & $120 \cdot 9$ & $58 \cdot 9$ & $21 \cdot 1$ & $111 \cdot 1$ & $51 \cdot 8$ \\
\hline & 1 & 42.5 & $148 \cdot 3$ & $78 \cdot 6$ & $5 \cdot 9$ & 84.5 & $32 \cdot 7$ & 38.4 & 141.4 & 73.6 & 31.4 & $129 \cdot 1$ & $64 \cdot 8$ & $21 \cdot 1$ & $111 \cdot 1$ & $51 \cdot 8$ \\
\hline
\end{tabular}

* Method 1 assumes all mass change is water, method 2 assumes part of the mass change is fat, method 3 assumes part of the mass change is protein - see Table 4) compared with DLW estimates derived from three separate calculation methods (see p. 83 for full details). Comparisons are generated using three different methods of evaluating the pool size (two plateau techniques $\mathrm{P}_{1-6}$ and $\mathrm{P}_{56}$ and one intercept technique I). Percentage difference was calculated as $100 \times$ the difference between each of the DLW equations and the three food intake-mass balance estimates, divided by the food intake-mass balance.

dosing involves only a slow perfusion of the body-water pools when compared with intravenous injection (used here). Moreover, urine sampling involves integration of samples derived from the body-water pool and stored in the bladder. It seems possible that the detection of significant effects of technique on the dilution space ratio, contrasting other studies, is at least partly because we used a method of labelling the pool that is more immediate (intravenous as opposed to oral), and also sampled directly from the bodywater pool (using blood as opposed to urine sampling).

The ratios derived from the intercept and the average plateau estimates over the first $6 \mathrm{~h}$ post-dosing averaged close to $1 \cdot 00$. This indicates both isotopes were predominantly in water during this early phase. This ratio is substantially lower than most previous evaluations of the dilution space ratio in man (reviewed in Speakman et al. 1993; Coward et al. 1994; Racette et al. 1994) and animals (Speakman, 1997), which generally indicate ratios in the range 1.01-1.10 (Speakman, 1997). In contrast the dilution space ratio for the late part of the plateau (1.0554) was similar to that measured in other animal studies (mean 1.0401 ), but considerably lower than previous measurements in dogs which suggested the ${ }^{2} \mathrm{H}$ space exceeded the body water by over $20 \%$ (Sheng \& Huggins, 1971). We suggest the differences observed in relation to time since injection reflect an initial phase $(<1 \mathrm{~h})$ during which both isotopes pervade the majority of the water space. Over the next $6 \mathrm{~h}$ both isotopes spread into less accessible water pools and subsidiary non-aqueous pools. Consequently, plateau estimates of dilution space ratio, at 5-6 h, yield a significantly greater value than $1 \cdot 0$, and in the same range as previous estimates. This indicates that sampling at 5-6 h post-dosing is necessary to obtain an appropriate estimate of the dilution space ratio in these animals.

\section{$\mathrm{CO}_{2}$ production}

There were large differences between the alternative calculations which was a consequence of the low ratio of the elimination constants. The highest results were found using the Lifson \& McClintock (1966) formulation. This equation is based on a single-pool model which assumes that excess flux of hydrogen occurs at the same rate as the extent of the excess hydrogen pool relative to the body water pool. The fact that this equation vastly overestimated the observed simultaneous $\mathrm{CO}_{2}$ production indicates that perhaps in this animal the subsidiary hydrogen flux is not very large and was thus insufficient to offset the differences in pool size for the two isotopes.

Although the two-pool model with the observed mean dilution space ratio of 1.0554 provided the best comparison between the indirect calorimetry and the DLW technique, the DLW still overestimated the $\mathrm{CO}_{2}$ production by, on average, $16 \%$. This overestimate was in part a consequence of the very large discrepancy found for dog 4 . The error for this individual was unlikely to be a consequence of an erroneous estimate of the body-water space (Table 1). As this animal had a low measured $\mathrm{CO}_{2}$ production by calorimetry for its body mass, we considered the large error might reflect a problem with the calorimetry. We therefore rescheduled calorimetry on this animal once isotope analysis had been completed and found a confirmatory 
low value. In addition, re-analysis of all the isotope samples produced confirmatory estimates to those originally generated. The discrepancy for this individual remains unexplained but could not be traced to analytical error in either calorimetry or DLW. The average discrepancy between the DLW estimates and the direct measurements (29-42\%) was considerably greater than the empirically determined analytical precision error in the DLW estimates (jacknife estimates), which varied between 1.7 and $7.8 \%$, indicating the error was not a simple consequence of imprecision in our isotope determinations. The discrepancy exceeded by far the results of previous validation studies, which on average across forty studies of vertebrates have a discrepancy of only $1.36 \%$ (Speakman, 1997). Some discussion of this error is therefore warranted.

Boyd et al. (1995) found an even greater overestimate in sea lions (Zalophus californiacus) that were exercising in a flume for about $22 \mathrm{~h}$. They suggested that part of this discrepancy was perhaps due to incorporation of oxygen into urea which would be particularly important in carnivores. This might lead to an excess oxygen flux additional to $\mathrm{CO}_{2}$ loss, which is not balanced by loss of hydrogen. This excess oxygen flux might then lead to overestimates of the $\mathrm{CO}_{2}$ production. This interpretation recalls an earlier suggestion that the different end products of $\mathrm{N}$ metabolism might underlie the slight overestimate of $\mathrm{CO}_{2}$ production observed in validation studies of mammals which is not evident in the same studies of birds or reptiles (Speakman, 1997). Since the present dogs were also fed a ration high in protein, incorporation of some oxygen into urea in the ornithine-arginine cycle would be expected. It is extremely unlikely, however, that this would lead to a gross overestimate in the $\mathrm{CO}_{2}$ production estimate by DLW. First, the amount of oxygen incorporated into urea in the ornithine-arginine cycle would be insufficient to produce an effect as great as an average $19 \%$ overestimate. Second, the urea molecule also contains four exchangeable hydrogen atoms. If these atoms also reached isotopic equilibrium the extra flux of oxygen would be more than accounted for by the extra flux of hydrogen. Since the exchangeable oxygen:hydrogen is 1:4 rather than 1:2 found in water a more likely consequence of high production of urea would be an under rather than an overestimate of $\mathrm{CO}_{2}$ production.

The most likely explanation for the overestimate reflects the protocol employed to estimate the $\mathrm{CO}_{2}$ production by respirometry. We removed the animals from the chamber for $1 \mathrm{~h}$ each day and discarded the first hour of each respirometry trial because of the lag and mixing properties of the chamber. During these $2 \mathrm{~h}$ the dogs had their greatest metabolic rates. In particular during the $1 \mathrm{~h}$ spent outside the chamber the dogs were very active when they were reunited with their handlers even though they were restrained on a leash. In addition, for the first hour back inside the chamber, the video tapes of activity revealed they moved about a lot. These activities would be expected to be connected with high levels of energy demand, which would be measured by DLW, but not by the calorimetry. We modelled the level of energy demand that would be necessary during these $2 \mathrm{~h}$ to generate the observed discrepancy. The model indicated an energy expenditure of about $4 \times$ BMR would be sufficient to match up to the two-pool model using the observed dilution spaces (Speakman, 1993) and an expenditure of $9 \times$ BMR would be required to generate the observed discrepancy to the singlepool model (Lifson \& McClintock, 1966). Since dogs may expend up to $23 \times$ BMR during vigorous exercise (Gorman et al. 1998) and we did not rigorously quantify the behaviour during the time spent out of the chamber we cannot separate which of the alternative equations is most suitable using the calorimetry data.

The suggestion that expenditure while not being monitored in the calorimeter explains the discrepancy between DLW and calorimetry estimates is supported by the comparison of the DLW technique to the food intakemass balance estimates of $\mathrm{CO}_{2}$ production. Food intake and mass balance as a method for estimating energy balance, and thus $\mathrm{CO}_{2}$ production, also accounts for the time the animals spent outside the chamber. Using this approach the comparisons to DLW were generally improved, although again on average overestimates occurred with all the different equations, and with all three of the methods for evaluating the energy equivalence of the mass changes. The least discrepancy occurred when it was assumed that the mass changes that had happened were actually only reflective of changes in hydration status of the animals, when using the Speakman (1993) equation the discrepancy averaged only $8.0 \%$. This average was however heavily influenced by a single overestimate of metabolism of $58 \%$ (Table 5). It seems possible that in most individuals the changes in mass were only changes in water content, but in this individual something different was happening. This would be consistent with the fact that energy equivalents of food intake alone always exceeded the calorimetry estimates of expenditure, except for this individual (Table 4, Fig. 4) indicating it was deriving energy from sources other than food. The discrepancy between DLW using the Speakman (1993) equation and the food intake-mass balance, assuming the withdrawn dry mass was fat, for this individual averaged only $+3.4 \%$. If it is assumed that this individual was withdrawing fat but in all the other individuals mass changes reflected only hydration status then the discrepancies between DLW and food intakemass balance average $16 \cdot 3 \%$ for the Lifson \& McClintock (1966) equation, $+3.8 \%$ for the Coward et al. (1985) equation, $+6 \cdot 1 \%$ for the Schoeller et al. (1986) equation A6, $+5.5 \%$ for the Speakman et al. (1993) equation and $0.31 \%$ for the Speakman (1993) equation.

The comparison to food intake suggests the overestimates of $\mathrm{CO}_{2}$ production using the DLW technique compared with indirect calorimetry were a consequence of the calorimetry protocol rather than any fundamental problem with the technique in its application to dogs. The mean comparison to $\mathrm{CO}_{2}$ production inferred from simultaneous food intake-mass balance $(0.31 \%$ for the best two-pool model) is similar to that found in previous validation studies. The extent of overestimate using the single pool model $(42.4 \%$ to indirect calorimetry and $16.3 \%$ to food intake) suggests the single-pool model is probably inappropriate for these animals. This result is in accord with the suggestion that the appropriateness of different formulations of the equation will depend on body 


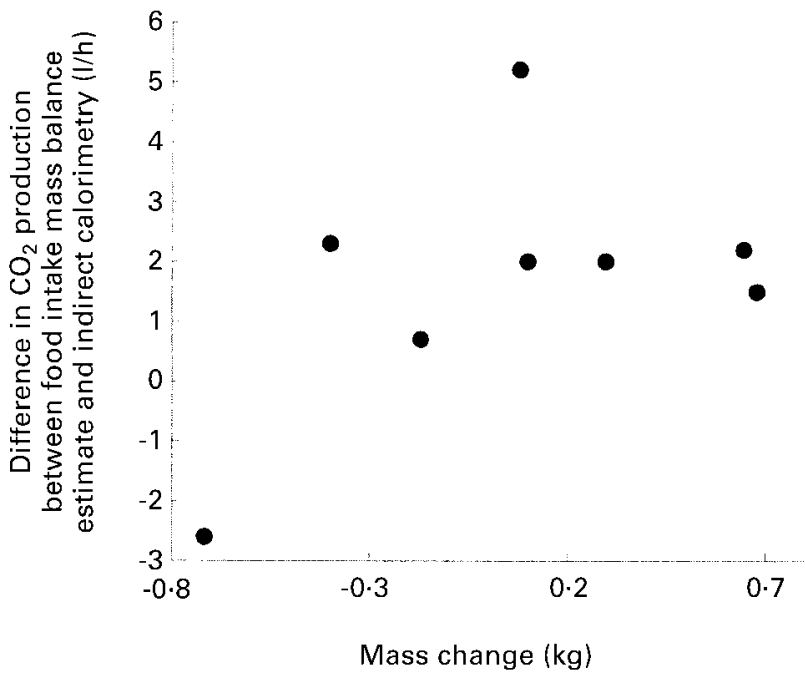

Fig. 4. Mass changes of eight Labrador dogs over the $4 \mathrm{~d}$ validation trial $v$. the difference between the carbon dioxide production evaluated from food intake and the direct estimate of carbon dioxide production by near continuous indirect calorimetry. One individual lost mass and had lower carbon dioxide production inferred from food intake than was actually measured. This individual must have withdrawn body reserves to account for this difference which is reflected in the mass loss. For the other individuals there was no significant relationship, suggesting mass changes in these individuals may have reflected mostly variation in water content.

size with larger animals $(>10 \mathrm{~kg})$ more likely to conform to the two-pool model.

This validation suggests that future studies of adult domestic dogs weighing $25-35 \mathrm{~kg}$ should employ the following protocol. The dogs should be left $5-6 \mathrm{~h}$ between dosing and removal of the equilibrium sample for evaluation of the dilution spaces. The dilution space should be evaluated from the plateau rather than the intercept. The elimination constants should be evaluated using multiple sampling and fitting of least squares regressions rather than using the two-sample approach. Finally, the $\mathrm{CO}_{2}$ production should be calculated using the two-pool equation and the group estimate of dilution space ratio (1.0554 in this instance).

\section{Acknowledgements}

This work was funded in part by a grant from the Waltham Centre for Pet Nutrition to the University of Aberdeen. We are grateful to Sandy Thorley for help handling the dogs.

\section{References}

Arnould J, Boyd I \& Speakman JR (1996) Measuring the body composition of antarctic fur seals (Arctocephalus gazella) by hydrogen isotope dilution. Physiological Zoology 69, 93-117.

Ballevre O, Anantharaman-Barr G, Gicquello P, Piguet-Welsh C, Thielin A-L \& Fern E (1994) Use of the doubly-labelled water method to assess energy expenditure in free-living cats and dogs. Journal of Nutrition 124, Suppl. 12, 2594S-2600S.

Bergmann BM, Everson CA, Kushida CA, Fang VS, Leitch CA, Schoeller DA, Refetoff S \& Rechtschaffen A (1989) Sleep deprivation in the rat. V. Energy use and mediation. Sleep 12, 31-41.

Bevan R, Speakman JR \& Butler PJ (1995) Validation of the heart rate and doubly labelled water techniques in tufted ducks. Functional Ecology 9, 40-48.

Boyd IL, Woakes AJ, Butler PJ, Davis RW \& Williams TM (1995) Validation of heart rate and doubly-labelled water as measures of metabolic rate during swimming in california sea lions. Functional Ecology 9, 151-160.

Bryant DM \& Westerterp KP (1983) Short-term variability in energy turnover by breeding house martins Delichon urbica: A study using doubly labelled water $\left(\mathrm{D}_{2}{ }^{18} \mathrm{O}\right)$. Journal of Animal Ecology 52, 525-543.

Burger I \& Johnson J (1990) Dogs large and small: The allometry of energy requirements within a single species. Journal of Nutrition 121, S18-S21.

Coleman ML, Shepherd TJ, Durham JJ, Rouse JE \& Morre GR (1982) Reduction of water with zinc for hydrogen isotope analysis. Analytical Chemistry 54, 993-995.

Coward WA, Prentice MA, Murgatroyd PR, Davies HL, Cole TJ, Sawyer M, Goldberg GR, Halliday D \& MacNamara JP (1985) Measurement of $\mathrm{CO}_{2}$ and water production rates in man using ${ }^{2} \mathrm{H},{ }^{18} \mathrm{O}$ labelled $\mathrm{H}_{2} \mathrm{O}$ : comparisons between calorimeter and isotope values. In European Nutrition Report 5: Human Energy Metabolism: Physical Activity and Energy Expenditure Measurements in Epidemiological Research Based upon Direct and Indirect Calorimetry, pp. 126-128 [AJH van Es, editor]. The Hague: CIP-gegevens Koninklijke Bibliotheek.

Coward WA, Ritz P \& Cole TJ (1994) Revision of calculations in the doubly labelled water method for measurement of energy expenditure in humans. American Journal of Physiology 267, E805-E807.

de Wit JC, van der Straaten CM \& Mook WG (1980) Determination of the absolute isotopic ratio of $\mathrm{V}-\mathrm{SMOW}$ and SLAP. Geostandards Newsletter 4, 33-36.

Fancy SG, Blanchard JM, Holleman DF, Kokjer KJ \& White RG (1986) Validation of the doubly-labelled water method using a ruminant. American Journal of Physiology 251, R143-R149.

Gorman ML, Mills MG, Raath JP \& Speakman JR (1998) High hunting costs make wild dogs vulnerable to keleptoparasitism by hyenas. Nature 391, 479-481.

Lifson N, Gordon GB, Visscher MB \& Nier AO (1949) The fate of utilised molecular oxygen and the source of the oxygen of respiratory carbon dioxide, studied with the aid of heavy oxygen. Journal of Biological Chemistry A 180, 803-811.

Lifson N, Gordon GB \& McClintock R (1955) Measurement of total carbon dioxide production by means of $\mathrm{D}_{2}{ }^{18} \mathrm{O}$. Journal of Applied Physiology 7, 704-710.

Lifson N \& McClintock R (1966) Theory of use of the turnover rates of body water for measuring energy and material balance. Journal of Theoretical Biology 12, 46-74.

Loveridge G (1994) Provision of environmentally enriched housing for dogs. Animal Technology 45, 1-19.

Matthews D \& Gilker DS (1995) Impact of ${ }^{2} \mathrm{H}$ and ${ }^{18} \mathrm{O}$ pool size determinations on the calculation of total energy expenditure. Obesity Research 3, Suppl. 1, 21-29.

Midwood AJ, Haggarty P \& McGaw BA (1993) The doublylabelled water method: errors due to deuterium exchange and sequestration in ruminants. American Journal of Physiology 264, R561-R567.

Mullen RK (1970) Respiratory metabolism and body water turnover rates of Perognatus formosus in its natural environment. Comparative Biochemistry and Physiology 32, 259-265.

Nagy KA (1972) Water and electrolyte budgets of a free-living desert lizard, Sauromalus obesus. Journal of Comparative Physiology 79, 39-62.

Nagy KA (1983) The Doubly Labelled Water $\left({ }^{3} \mathrm{HH}^{18} \mathrm{O}\right)$ Method: a 
Guide to its Use. UCLA Publication 12-1417. Los Angeles, CA: UCLA.

Nagy KA, Sanson GD \& Jacobsen NK (1990) Comparative field energetics of two macropod marsupials and a ruminant. Australian Wildlife Research 17, 591-599.

Prentice AM (1990) The Doubly Labelled Water Method for Measuring Energy Expenditure, Technical Recommendations for Use in Humans. Vienna: International Atomic Energy Agency.

Racette SB, Schoeller DA, Luke AH, Shay K, Hnilicka J \& Kushner RF (1994) Relative dilution spaces of ${ }^{2} \mathrm{H}$ - and ${ }^{18} \mathrm{O}-$ labelled water in humans. American Journal of Physiology 30, E585-E590.

Roberts SB (1989) Use of the doubly labelled water method for measurement of energy expenditure, total body water, water intake and metabolisable energy intake in humans and small animals. Canadian Journal of Physiology and Pharmacology 67, 1190-1198.

Robinson I (1995) The Waltham Book of Human-Animal Interaction. Benefits and Responsibilities of Pet Ownership. London: Pergamon.

Schmidt-Nielsen K (1975) Animal Physiology: Adaptation and Environment. Cambridge: Cambridge University Press.

Schoeller DA, Ravussin E, Schutz Y, Acheson KJ, Baertschi P \& Jequier E (1980) Energy expenditure by doubly labelled water: validation in humans and proposed calculation. American Journal of Physiology 250, R823-R830.

Schoeller DA \& Santen E (1982) Measurement of energy expenditure in humans by doubly labelled water. Journal of Applied Physiology 53, 955-959.

Sheng HP \& Huggins RA (1971) Direct and indirect measurement of total body water in the growing beagle. Proceedings of the Society for Experimental Biology and Medicine 137, 10931099.

Speakman JR (1993) How should we calculate $\mathrm{CO}_{2}$ production in DLW studies of animals? Functional Ecology 7, 746-750.

Speakman JR (1995) Empirical estimation of precision in the doubly labelled water method. Obesity Research 3, Suppl. 1, 21-29.

Speakman JR (1997) Doubly-labelled Water: Theory and Practice. London: Chapman \& Hall.

Speakman JR, Nair KS \& Goran MI (1993) Revised equations for calculating $\mathrm{CO}_{2}$ production from doubly labelled water in humans. American Journal of Physiology 264, E912-E917.

Tiebout HM III \& Nagy KA (1991) Validation of the doublylabelled water method $\left({ }^{3} \mathrm{HH}^{18} \mathrm{O}\right)$ for measuring water flux and $\mathrm{CO}_{2}$ production in the tropical hummingbird Amazilla saucerottei. Physiological Zoology 64, 362-374.

Wells JCK, Ritz P, Davies PSW \& Coward WA (1998) Factors affecting the H-2 to O-18 dilution space ratio in infants. Pediatric Research 43, 467-471.

Wong WWCochran WJKlish WJSmith EOLee LSKlein PD (1988) In vivo isotope fractionation factors and the measurement of deuterium- and oxygen-18-dilution spaces from plasma, urine, saliva, respiratory water vapour, and carbon dioxide. American Journal of Clinical Nutrition 47, 1-6. 